\title{
Home Oxygen Therapy for Patients With COPD: Time for a Reboot
}

\author{
Jennifer A Sculley, Susan J Corbridge, Valentin Prieto-Centurion, Thomas J Kallstrom, \\ Joseph Lewarski, Ai-Yui M Tan, and Jerry A Krishnan
}

\author{
Introduction \\ Evidence Supporting the Use of Long-Term Oxygen Therapy \\ Home Oxygen Therapy for Severe Resting Room Air Hypoxemia \\ Home Oxygen Therapy for Moderate Resting Room Air Hypoxemia \\ Ambulatory Oxygen Therapy for Exertional Desaturation \\ Short-Term Oxygen Therapy \\ Description of Home Oxygen Equipment \\ Stakeholder Perspectives About Home Oxygen Therapy During Hospital \\ to Home Transitions \\ Patients and Caregivers \\ Durable Medical Equipment Providers \\ Front-Line Hospital-Based and Outpatient Clinicians \\ Appropriate Home Oxygen Therapy Depends on a Successful Chain of \\ Care During Transition From Hospital to Home \\ How to Strengthen the Chain of Home Oxygen Care During Transitions \\ From Hospital to Home \\ Resume Long-Term Oxygen Therapy Consensus Conference \\ Series With a Full Complement of Stakeholders \\ Leverage the Framework Proposed by the U.S. COPD National Action Plan
}

\begin{abstract}
Just over 100 years ago, John Scott Haldane published a seminal report about the therapeutic potential of supplemental oxygen to treat hypoxemia. In the 1980s, a pair of clinical trials confirmed the benefit of long-term oxygen therapy in improving survival in patients with COPD associated with severe resting hypoxemia. This review provides a summary of evidence supporting long-term and short-term oxygen therapy, as well as the various types of oxygen equipment commonly used in homes to deliver supplemental oxygen. Because the majority of orders for home oxygen occur at hospital discharge following acute illness, a typical conversation between a patient and their pulmonologist following a COPD exacerbation is presented. The SHERLOCK Consortium, a multistakeholder group established following the publication of the COPD National Action Plan in 2017 is also detailed. Interim results of the SHERLOCK Consortium, which suggest a chain of care involving 9 steps to ensure that patients are successfully initiated on home oxygen therapy during transitions from hospital to home, are presented. Recommendations to support evidence-based policies in this high-risk population are provided. [Respir Care 2019;64(12):1574-1585. (C) 2019 Daedalus Enterprises]
\end{abstract}

Introduction

Home oxygen therapy has been a standard of care for COPD over the last 40 years. The process of qualifying a patient for home oxygen, determining the right prescrip- tion, providing the right equipment, and educating caregivers, however, remains a challenge. The chain of care required to deliver appropriate and effective home oxygen therapy is complex and obfuscated by federal regulations. This challenge also is an opportunity: We believe home 
oxygen therapy needs a complete re-evaluation focusing on patient needs and patient education to maximize oxygen therapy benefits.

\section{Evidence Supporting the Use of Long-Term Oxygen Therapy}

Very few individuals have contributed as much to pulmonary medicine as John Scott Haldane, considered by many to be the "father" of oxygen therapy (1860-1936; Fig. 1). ${ }^{1,2}$ Haldane investigated the composition of air, identified gases that led to suffocation in coal mines, researched the physiologic effects of low barometric pressure, discovered the role of carbon dioxide in the control of breathing, explored the beneficial effects of staged decompression that make it possible for deep-sea divers to return to the surface safely, and developed the precursor of modern-day blood-gas analysis. ${ }^{3-11}$ Just over 100 years ago, Haldane published a seminal report about the therapeutic potential of supplemental oxygen. ${ }^{7}$ Sixty years after this publication, a pair of randomized clinical trials in a total 290 people confirmed the survival benefits of longterm oxygen therapy (LTOT) in subjects with COPD and severe resting hypoxemia. ${ }^{12,13}$

\section{Home Oxygen Therapy for Severe Resting Room Air Hypoxemia}

The Medical Research Council (MRC) multi-center clinical trial randomized 87 people with COPD to LTOT via nasal cannula for at least $15 \mathrm{~h} / \mathrm{d}$ with a target $\mathrm{P}_{\mathrm{aO}_{2}}$ of $60 \mathrm{~mm} \mathrm{Hg}$ or higher versus no home oxygen. ${ }^{12}$ To be eligible, subjects needed to be $<70$ years old, have chronic bronchitis or emphysema with "irreversible airway obstruction" (defined as $\mathrm{FEV}_{1}<1.2 \mathrm{~L}$ ), and resting room air

\footnotetext{
Ms Sculley and Drs Corbridge, Prieto-Centurion, Tan, and Krishnan are affiliated with the University of Illinois at Chicago. Mr Kallstrom is affiliated with the American Association for Respiratory Care, Irving, Texas. Mr Lewarski is affiliated with Drive DeVilbiss Healthcare, Port Washington, New York.
}

Dr Krishnan presented a version of this paper at the 6th Thomas L Petty Memorial Lecture at the 2018 AARC International Respiratory Congress, held December 4-7, 2018, in Las Vegas, Nevada.

Dr Corbridge discloses relationships with the Rita and Alex Hillman Foundation, the Health Resources \& Services Administration, and Medical Communications Media/Boehringer Ingelheim/American Academy of Nurse Practitioners. Dr Prieto-Centurion discloses relationships with the National Institutes of Health (NIH) and ResMed. Mr Kallstrom is an employee of the American Association for Respiratory Care. Mr Lewarski is an employee of Drive DeVilbiss Healthcare. Dr Tan discloses a relationship with the NIH. Dr Krishan discloses relationships with the $\mathrm{NIH}$ and the Patient-Centered Outcomes Research Institute. Ms Sculley has disclosed no conflicts of interest.
$\mathrm{P}_{\mathrm{aO}_{2}}$ of $40-60 \mathrm{~mm} \mathrm{Hg}$. Subjects with evidence of cor pulmonale were hospitalized and needed to demonstrate stable arterial blood gas, $\mathrm{FEV}_{1}$, and weight over a period of at least 3 weeks to be eligible.

Once enrolled, all study subjects were urged to stop smoking and had close follow-ups that included an outpatient clinic visit every 2 months. Subjects in the home oxygen group received oxygen through various types of equipment, including a stationary oxygen concentrator, reservoir of liquid oxygen, or compressed gas tanks. Participants in the home oxygen group also received periodic home visits (frequency not specified) to assess oxygen usage and collect arterial blood gases; this information was used to promote appropriate use of home oxygen among the subjects in the intervention group. At 5 years, 19 of 42 subjects $(42 \%)$ in the home oxygen therapy group had died, compared to 30 of 45 patients $(66 \%)$ in the usual care (no home oxygen) group. The 5-year relative risk of death was 0.41 (95\% CI 0.17-0.98) favoring the home oxygen group compared to the no home oxygen group. When interpreting these results, it is important to remember that home visits to carefully titrate the oxygen prescription and equipment to individual needs likely contributed to the survival benefits observed in the intervention group.

The multi-center Nocturnal Oxygen Therapy Trial (NOTT) sought to determine whether LTOT prescribed $24 \mathrm{~h} / \mathrm{d}$ offered benefits beyond that observed when LTOT is prescribed for nighttime use only. ${ }^{13}$ In the NOTT study, 203 subjects with COPD were randomized to continuous LTOT (ie, $24 \mathrm{~h} / \mathrm{d}$ ) or nocturnal LTOT. To be eligible, individuals needed to be at least 35 years old, have COPD confirmed with post-bronchodilator $\mathrm{FEV}_{1} / \mathrm{FVC}<0.70$, and have severe resting room air hypoxemia $\left(\mathrm{P}_{\mathrm{aO}_{2}} \leq\right.$ $55 \mathrm{~mm} \mathrm{Hg}$ or $\mathrm{P}_{\mathrm{aO}_{2}} 56-59 \mathrm{~mm} \mathrm{Hg}$ with evidence of erythrocytosis or cor pulmonale). The study protocol required confirmation of severe hypoxemia twice, assessed at least 1 week apart over a 3-week COPD exacerbation-free period. Patients were excluded if they had clinically important comorbid conditions expected to affect morbidity or mortality or if there were concerns about nonadherence to therapy.

In the NOTT study, LTOT was delivered by nasal cannula at $1-4 \mathrm{~L} / \mathrm{min}$ with a target $\mathrm{P}_{\mathrm{aO}_{2}}$ of $60-80 \mathrm{~mm} \mathrm{Hg}$ for all subjects. The oxygen prescription in the continuous LTOT group was increased by $1 \mathrm{~L} / \mathrm{min}$ during exercise and sleep. As with the MRC study, the oxygen equipment for study participants included stationary oxygen concen-

Correspondence: Jerry A Krishnan MD PhD, Mile Square Health Center, University of Illinois at Chicago, 1220 S. Wood Street, Room 3002 (MC 619), Chicago, IL 60608. E-mail: jakris@uic.edu.

DOI: $10.4187 /$ respcare. 07135 


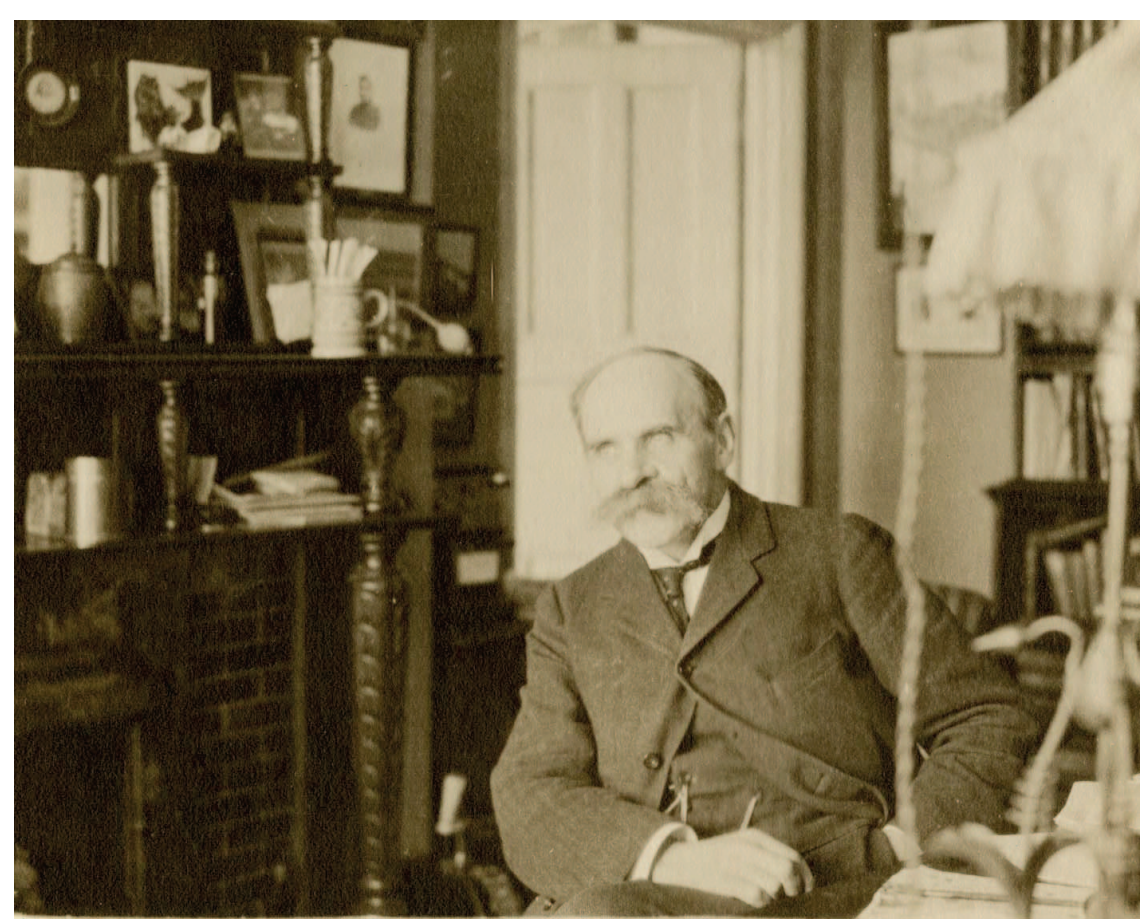

Fig. 1. John Scott Haldane was born May 3, 1860, in Edinburgh, Scotland, and is considered to be the father of oxygen therapy.

trators, liquid oxygen systems, and compressed oxygen tanks. Importantly, the stationary concentrators and oxygen reservoirs were outfitted with timers that recorded the duration of gas flow. This information was used to estimate adherence to LTOT, although this method underestimated total oxygen use if patients also used portable equipment for liquid oxygen or small tanks of compressed gas.

Subjects in both groups in the NOTT study appeared to have even more intensive support than those in the LTOT group in the MRC study. All NOTT subjects were assessed during home visits by a nurse practitioner once per week and were asked to attend out-patient clinic appointments once per month for 6 months; then, NOTT participants received home visits once per month and were asked to attend clinic visits every 3 months for the duration of the study.

Data from oxygen timers on stationary equipment suggested that oxygen was used for about $18 \mathrm{~h} / \mathrm{d}$ in the continuous LTOT group and for about $12 \mathrm{~h} / \mathrm{d}$ in the nocturnal LTOT group. The NOTT subjects were followed for a mean of 19.3 months. At 12 and 24 months, mortality in the continuous LTOT group was lower than in the nocturnal LTOT group (11.9\% vs $20.6 \%$ and $22.4 \%$ vs $40.8 \%$, respectively). Overall mortality significantly favored the continuous LTOT group compared to the nocturnal LTOT group (relative risk $0.52,95 \%$ CI $0.31-0.85$ ). Whether these benefits would be observed in the absence of intensive home and out-patient clinic supports is unknown. For example, it is possible that, without such support, subjects in both groups would not know how to use the LTOT equipment properly, which would lead to no observed difference in outcomes between groups. Such support is often not available to patients prescribed LTOT today.

\section{Home Oxygen Therapy for Moderate Resting Room Air Hypoxemia}

The survival benefits of LTOT do not appear to accrue to individuals with COPD who have less than severe resting hypoxemia. In the Long-term Oxygen Therapy Trial (LOTT), 738 subjects with COPD and moderate resting hypoxemia $\left(\mathrm{S}_{\mathrm{pO}_{2}} 89-93 \%\right)$, exercise-induced hypoxemia during a 6-min walk test $\left(\mathrm{S}_{\mathrm{pO}_{2}}<90 \%\right.$ for at least $10 \mathrm{~s}$ and $\mathrm{S}_{\mathrm{pO}_{2}}$ at least $80 \%$ for at least $5 \mathrm{~min}$ ), or both were randomized to LTOT or no oxygen. ${ }^{14}$ LTOT was prescribed $24 \mathrm{~h} / \mathrm{d}$ using stationary and portable oxygen equipment in subjects who had moderate resting hypoxemia, but with exercise and during sleep in subjects who only had exercise-induced hypoxemia. In the former group, LTOT was prescribed at $2 \mathrm{~L} / \mathrm{min}$ via nasal cannula. In the latter group, the oxygen prescription was individualized $(2 \mathrm{~L} / \mathrm{min}$ or higher to maintain $\mathrm{S}_{\mathrm{pO}_{2}}$ at least $90 \%$ while walking for at least $2 \mathrm{~min}$ ) and reassessed annually. As with the MRC and NOTT studies, the assignment of oxygen was not masked to subjects or study staff.

Among all 738 subjects, there were no discernable differences in time to death or first hospitalization (primary 
outcome; hazard ratio $0.94,95 \%$ CI $0.79-1.12, P=.52$ ) over 6 years in both study groups. Similar findings were noted for the primary outcome in the 133 subjects who had moderate resting hypoxemia only (prescribed LTOT vs no oxygen: hazard ratio $0.96,95 \%$ CI $0.63-1.47$ ) and in the 286 subjects with both moderate resting hypoxemia and exertional desaturation (hazard ratio $0.95,95 \%$ 0.72-1.27). In addition, the study did not find consistent benefits with home oxygen therapy in any of the numerous secondary outcomes among all subjects (eg, components of the primary outcome, quality of life, lung function, distance walked in $6 \mathrm{~min}$ ). Taken together, these 3 studies (NOTT, MRC, and LOTT) provide strong evidence that home oxygen prescribed for at least $15 \mathrm{~h} / \mathrm{d}$ saves lives for patients with COPD and severe, but not for patients with moderate resting hypoxemia. ${ }^{15}$

\section{Ambulatory Oxygen Therapy for Exertional Desaturation}

Ambulatory oxygen therapy refers to oxygen delivered during exercise or other activities of daily living. The LOTT study adds to the existing literature about the benefits of ambulatory oxygen therapy. Prior to LOTT, there were 4 randomized clinical trials of ambulatory oxygen therapy in total of 237 subjects (26-143 participants subjects per study) with COPD and exertional dyspnea or desaturation without evidence of severe resting hypoxemia. ${ }^{16-19}$ All 4 studies compared portable oxygen or identical appearing compressed air over a 2-12-week period; subjects and study staff were masked to treatment assignment. A metaanalysis of these studies suggests the potential to improve dyspnea and fatigue with exertion. ${ }^{20}$ The LOTT study results indicated no significant difference among the those prescribed LTOT versus no oxygen for the primary outcome (death or first hospitalization) in the 286 subjects who had exertional desaturation with moderate resting hypoxemia (results presented above) and in the 319 subjects with exertional desaturation without moderate hypoxemia (hazard ratio $0.95,95 \%$ CI $0.73-1.24$ ). ${ }^{14}$ These 5 randomized clinical trials involving a total of nearly 850 people with COPD suggest the need for a more nuanced approach to treating exertional desaturation in the absence of severe resting hypoxemia. Such individuals may benefit from a discussion with their health care provider to understand their preferences and values for the treatment of dyspnea and fatigue (ie, shared decision making), ${ }^{21}$ rather than routinely prescribing ambulatory oxygen therapy in this population.

\section{Short-Term Oxygen Therapy}

Short-term oxygen therapy refers to initiating oxygen during a period of severe hypoxemia that is likely to be temporary (eg, during a COPD exacerbation). Studies in subjects who are prescribed home oxygen during a respiratory exacerbation (most of whom have COPD or are hospitalized for a COPD exacerbation) suggest that $30-$ $50 \%$ of such individuals no longer have severe resting hypoxemia within 3 months. ${ }^{22,23}$ Guidelines therefore recommend re-assessing home oxygen requirements after hospital discharge to modify the oxygen prescription (eg, reductions or increases in oxygen flow, prescribing portable equipment) or to discontinue it altogether in patients who no longer have a clinical indication. ${ }^{15,24}$ Dedicated oxygen clinics that re-assess a patient's need for continuing home oxygen after hospital discharge and provide patient education can help implement these guideline recommendations. ${ }^{22}$ However, dedicated home oxygen clinics are not routine in most health systems; findings from a multicenter qualitative study suggest that patients who are prescribed home oxygen are not routinely re-assessed for their home oxygen need, which may lead some to use home oxygen even when they do not need it. ${ }^{25}$

\section{Description of Home Oxygen Equipment}

Several types of equipment deliver oxygen for home use: stationary equipment to be used at home (eg, stationary concentrator), portable equipment to be used outside the home (eg, portable oxygen concentrators, compressed oxygen tank, liquid oxygen system), and accessories for use with portable and stationary equipment (eg, home transfill unit, oxygen-conserving device) (Fig. 2). Most patients need a combination of stationary and portable oxygen equipment. In some cases, patients use an oxygen-conserving device on their compressed oxygen tanks; such devices provide oxygen only during inspiration to extend the time that each tank can be used.

Compressed oxygen tanks are time-limited sources of oxygen; the duration of use varies across different compressed oxygen tanks according to the size of the tank (in order of size: M4, M6, D, E), filling pressure, oxygen flow, and whether an individual is using continuous flow oxygen or an oxygen conserving device. According to information provided to patients by a home health provider, a D-cylinder filled to 2,000 pounds per square inch and used at 2, 3, and $4 \mathrm{~L} / \mathrm{min}$ continuous flow will last approximately $2,1.25$, and $1 \mathrm{~h}$, respectively; corresponding durations of use for a E-cylinder are approximately $4.5,3$, and $2 \mathrm{~h}$, respectively. ${ }^{26}$ Information published by a durable medical equipment (DME) provider suggests slightly different information (ie, a D-cylinder at $4 \mathrm{~L} / \mathrm{min}$ continuous flow will last $1.7 \mathrm{~h}$, whereas an E-cylinder used at $4 \mathrm{~L} / \mathrm{min}$ continuous flow will last $2.8 \mathrm{~h}$ ). ${ }^{27} \mathrm{~A}$ reliable resource developed and maintained by an independent group without commercial interests in the home oxygen equipment is needed. 


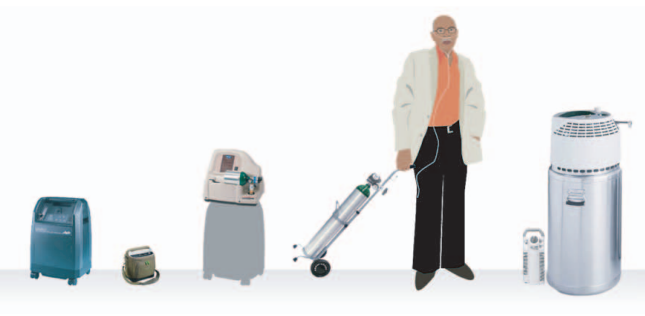

\begin{tabular}{|c|c|}
\hline Type of equipment & Description \\
\hline $\begin{array}{l}\text { Oxygen concentrator } \\
\text { Stationary }\end{array}$ & $\begin{array}{l}\text { - Device that concentrates oxygen from ambient air } \\
\text { - Designed to be used in the home } \\
\text { - Requires constant power supply }\end{array}$ \\
\hline $\begin{array}{l}\text { Oxygen concentrator } \\
\text { Portable }\end{array}$ & $\begin{array}{l}\text { - Device that concentrates oxygen from ambient air } \\
\text { - Lightweight; designed to be used outside the home } \\
\text { - Internal battery allows several hours of use between charges }\end{array}$ \\
\hline $\begin{array}{l}\text { Home transfill } \\
\text { Accessory }\end{array}$ & $\begin{array}{l}\text { - Device to fill compressed oxygen tanks from oxygen delivered by } \\
\text { stationary oxygen concentrator } \\
\text { - Attached to stationary oxygen concentrator } \\
\text { - Designed to be used in the home }\end{array}$ \\
\hline $\begin{array}{l}\text { Compressed oxygen } \\
\text { tank } \\
\text { Portable }\end{array}$ & $\begin{array}{l}\text { - Compressed gas cylinder } \\
\text { - Designed to be used outside of the home } \\
\text { - Usually filled by a patient or caregiver using a home transfill system } \\
\text { or by a DME company who delivers it to the home } \\
\text { - Duration depends on prescribed flow }\end{array}$ \\
\hline $\begin{array}{l}\text { Oxygen conserving } \\
\text { device } \\
\text { Accessory }\end{array}$ & $\begin{array}{l}\text { - Accessory that sits atop compressed oxygen tanks } \\
\text { - Controls the flow of oxygen such that it releases only when the } \\
\text { patient inhales } \\
\text { - Designed to extend the duration of compressed oxygen tanks used } \\
\text { outside of the home } \\
\text { - Not all patients can maintain appropriate oxygen saturation using an } \\
\text { oxygen conserving device }\end{array}$ \\
\hline $\begin{array}{l}\text { Liquid oxygen system } \\
\text { Portable }\end{array}$ & $\begin{array}{l}\text { - Liquid oxygen in the tank vaporizes to provide a steady flow of oxygen } \\
\text { - Lightweight tank has prolonged duration of delivery } \\
\text { - Filled by patient or caregiver from a home reservoir installed by } \\
\text { DME company } \\
\text { - Capable of delivering oxygen flow (>6 L/min) }\end{array}$ \\
\hline
\end{tabular}

Fig. 2. There are different types of home oxygen equipment that patients can use: stationary equipment to be used at home, portable equipment to be used outside the home, and accessories for use with portable and stationary equipment. DME = durable medical equipment.

Portable oxygen concentrators can provide continuous flow oxygen (oxygen delivered at a constant flow, not triggered by an inspiratory effort), pulse-dose oxygen (oxygen delivered during inspiration only; the quantity of oxygen delivered is influenced by the breathing frequency), or both. Options for oxygen delivery using portable oxygen concentrators can vary by manufacturer. $^{28}$ 
Table 1. An Outpatient Visit With Mr. Carter* After Starting Home Oxygen

\begin{tabular}{|c|c|}
\hline Pulmonologist: & $\begin{array}{l}\text { Hello Mr. Carter. Thank you for coming to see us today for your follow-up appointment. I understand you had trouble } \\
\text { breathing and were hospitalized for your COPD for about } 5 \text { days, and now you have been home for about } 10 \text { days. } \\
\text { How are you doing today? }\end{array}$ \\
\hline Mr. Carter: & I am having difficulty catching my breath. \\
\hline Pulmonologist: & $\begin{array}{l}\text { (after reviewing vital signs) I am sorry to hear that. Let's see how we can help. You don't have a fever, but the } \\
\text { nurse's note says your oxygen level is } 84 \% \text {, which is lower than what we have seen in past clinic visits. Are you } \\
\text { coughing or bringing up phlegm? }\end{array}$ \\
\hline Mr. Carter: & $\begin{array}{l}\text { I was coughing up phlegm when I was admitted to the hospital, but all that got better after taking the prednisone and } \\
\text { antibiotics. Not much cough or phlegm now, just trouble catching my breath when I don't wear my oxygen. }\end{array}$ \\
\hline Pulmonologist: & $\begin{array}{l}\text { I don't see that you brought an oxygen tank or a portable oxygen concentrator with you today. Were you asked to use } \\
\text { oxygen after leaving the hospital? }\end{array}$ \\
\hline Mr. Carter: & $\begin{array}{l}\text { They asked me to wear oxygen } 24 / 7 \text { after going home and to check with you if I still needed it. It was a big machine } \\
\text { that they set up near my bed, which I am supposed to use at } 2 \text {. They also dropped off a bunch of tanks. Don't see } \\
\text { how I can use the tanks when I get out of the house because they are too heavy to carry around and they don't last } \\
\text { more than an hour or so. Not enough time for me to get from home to your office and back to home. I also didn't } \\
\text { know how to change tanks when the first one I was given ran out about a week ago. }\end{array}$ \\
\hline Pulmonologist: & $\begin{array}{l}\text { I see in the hospital discharge summary that you were prescribed home oxygen at } 2 \mathrm{~L} / \mathrm{min} \text {. I don't see how much } \\
\text { oxygen was prescribed when walking or during sleep or the type of oxygen equipment you were provided. Do you } \\
\text { know how low your oxygen level was when they decided to prescribe home oxygen before you left the hospital? }\end{array}$ \\
\hline Mr. Carter: & $\begin{array}{l}\text { Isn't the information in the computer? I don't remember if they told me about my oxygen level. I also don't } \\
\text { remember if I should use more oxygen when I am walking than when I am sitting, but it sure helps me breathe } \\
\text { better when I increased the oxygen level to } 6 \text {. But then the tank got empty quick. }\end{array}$ \\
\hline
\end{tabular}

This is a typical conversation between a patient and his pulmonologist following hospitalization for a COPD exacerbation.

* Name changed to protect the patient's privacy.

In a study of 507 subjects with COPD prescribed LTOT, subjects reported $>25$ different combinations of home oxygen equipment. The 3 most common combinations were a stationary concentrator and compressed oxygen tanks with an oxygen-conserving device (24\%), a stationary concentrator and compressed oxygen tanks without an oxygen-conserving device (17\%), and a stationary concentrator and a portable concentrator (11\%). ${ }^{29}$ These findings suggest that a substantial proportion of people are using compressed oxygen tanks rather than portable oxygen concentrators as their source of oxygen when outside the home. The inconvenience of compressed oxygen tanks (heavy to lift and to transport, especially for elderly patients or those with limited respiratory reserve; need for multiple tanks if the period of time outside the home is greater than a few hours) explains in part why patients only use $45-70 \%$ of the oxygen prescribed. ${ }^{30-33}$ Other factors that contribute to variable levels of adherence to oxygen therapy include inadequate understanding of the risks and benefits of oxygen therapy, limited self-efficacy in the use of home oxygen equipment, and stigma associated with using supplemental oxygen in public. These findings suggest the need for patient support, including education, and for equipment that is light-weight, unobtrusive, and easy to use.

Table 1 describes a typical conversation between a patient and his physician following a hospital admission for a COPD exacerbation. The pulmonologist, a physician who is seeing Mr Carter at a Veterans Administration Medical
Center (VAMC), requested a 6-min walk test by a respiratory therapist in the pulmonary function laboratory adjacent to the out-patient clinic. The test confirmed that the severe resting room air hypoxemia was corrected with oxygen delivered continuously at $2 \mathrm{~L} / \mathrm{min}$, but that $\mathrm{Mr}$ Carter needed $3 \mathrm{~L} /$ min to maintain a $\mathrm{S}_{\mathrm{pO}_{2}}$ of $90 \%$ when walking. Mr Carter was prescribed home oxygen continuously at $2 \mathrm{~L} / \mathrm{min}$ at rest, $3 \mathrm{~L} / \mathrm{min}$ with activity, and (empirically) $3 \mathrm{~L} / \mathrm{min}$ during sleep. Mr Carter does not qualify for a portable oxygen concentrator because at the VAMC this type of device is reserved for veterans who travel out-of-town, and Mr Carter could not afford to purchase a light-weight portable oxygen concentrator, which can cost between $\$ 1,500$ and $\$ 3,000$. Mr Carter was therefore prescribed a stationary oxygen concentrator when at home and oxygen cylinders (E-cylinders) for use when he leaves home, to be set at $2 \mathrm{~L} / \mathrm{min}$ continuous flow at rest and $3 \mathrm{~L} / \mathrm{min}$ continuous flow with exertion. He received education about the benefits and risks of home oxygen therapy and the appropriate use of his oxygen equipment, including how to safely change the regulator when his oxygen cylinder runs out and to avoid being close to an open flame or someone smoking a cigarette. Mr Carter agreed to join the VAMC's telemedicine program, which offers a pulse oximeter at no cost to check the adequacy of oxygen supplementation and to guide subsequent decisions to change the oxygen prescription. The clinic staff provided Mr Carter with a filled E-cylinder for his return trip to home. He was informed that this E-cylinder would last about $4 \mathrm{~h}$ at $2 \mathrm{~L} / \mathrm{min}$ 
(and $3 \mathrm{~h}$ at $3 \mathrm{~L} / \mathrm{min}$, which was sufficient for his 2-h trip to home) and was asked to return to the clinic in 4 weeks to re-assess his home oxygen needs. He was instructed to wear his oxygen $24 \mathrm{~h} / \mathrm{d}$ for now, but that follow-up visits would be needed to learn whether his oxygen equipment helped him with activities of daily living and to evaluate his need for short-term oxygen therapy versus LTOT. As Mr Carter left clinic, his pulmonologist worried that the oxygen cylinders were likely too inconvenient for Mr Carter to use as prescribed when he leaves home.

The situation with Mr Carter is not uncommon. When a patient is discharged to home following a hospitalization for a COPD exacerbation, they are sometimes prescribed short-term oxygen therapy, especially if oxygen therapy allows the patient to be safely discharged from the hospital sooner. However, the details regarding the evaluation or prescription in the hospital are often poorly documented, missing altogether, or simply unavailable to the patient, their caregivers, and their out-patient clinician. ${ }^{34}$ Also, patients initiated on home oxygen in the hospital often receive inadequate education about their options for home oxygen equipment and how to use the equipment, or they do not have appropriate, affordable access to the equipment that is right for them. ${ }^{25} \mathrm{In}$ the case of Mr Carter, a light-weight portable concentrator for ambulation may have been the best device. ${ }^{35,36}$ Patients, their caregivers, and their out-patient clinicians are therefore frustrated with the care that is currently accessible.

A group of front-line, hospital-based, and out-patient physicians, respiratory therapists, nurses, patients, their caregivers, DME providers, and representatives of the American Association for Respiratory Care (AARC) and the American Thoracic Society (ATS) have begun to examine gaps in home oxygen care following hospital discharge in patients with COPD. The group, known as the SHERLOCK Consortium, includes about 170 stakeholders, including 47 patients and their caregivers, 83 hospital-based and out-patient clinicians (40 physicians, 17 respiratory therapists, 11 nurses, 15 social workers and other clinicians), 4 hospital discharge planners, 4 DME providers, 16 researchers, and 17 other individuals with expertise in COPD or home oxygen policies. The SHERLOCK Consortium was established following the publication of the COPD National Action Plan in 2017, ${ }^{37}$ the first-ever framework for action in the United States to reduce the public health impact of COPD in the United States.

In the sections that follow, we describe the interim findings of the SHERLOCK Consortium that highlight opportunities to develop an evidence base to support better care and health for patients with COPD who are prescribed home oxygen during hospital-to-home transitions. Some aspects of this report were presented during the sixth Thomas L Petty Memorial Lecture on "Everyone Needs
Oxygen" at the 2018 AARC International Respiratory Congress (December 4-7, 2018, Las Vegas). ${ }^{38}$

\section{Stakeholder Perspectives About Home Oxygen Therapy During Hospital to Home Transitions}

We provide below a synthesis of perspectives of three stakeholder groups in the SHERLOCK Consortium: patients and their caregivers, DME providers, and front-line clinicians.

\section{Patients and Caregivers}

Mr Carter's experience after being started on home oxygen therapy is not unique. In February 2017, people with COPD and their families attended a health education workshop about home oxygen in Florida, convened by the Villages Airheads (a patient support group), the COPD Foundation (a non-profit organization that supports education, research, and policies to support the needs of people with COPD), ${ }^{39}$ clinicians, and researchers from the SHERLOCK Consortium.

Workshop participants expressed a high level of frustration about gaps in care and information about home oxygen therapy. Participants had numerous questions about practical aspects of living with home oxygen, including how long they would need to use oxygen, performance characteristics (eg, size, weight, noise level, battery life, adequacy of oxygen flow) of various types of stationary and portable oxygen concentrators, quality of services provided by different DME providers, out-of-pocket costs of various types of equipment and disposables (eg, nasal cannula, humidifiers), options during air travel, safety of using home oxygen during a shower, how to troubleshoot when their oxygen equipment malfunctions, and assessing the adequacy of their home oxygen prescription with changes in respiratory symptoms.

Clinicians felt that they were mostly unprepared to answer the questions with the level of detail that workshop participants wanted, so we asked participants to submit their questions in writing and, with the help of the AARC and the COPD Foundation, produced a Frequently Asked Questions and Answers document that was made available after the workshop (Table 2)..$^{40}$ Participants identified an ongoing need for an independent and trustworthy source of updated information to supplement what they were able to learn from their physician offices, DME providers, and other content that may be available online-similar to what is available through Consumer Reports for other products and services. ${ }^{41}$ Participants also supported the development of a national oxygen equipment registry to facilitate public reporting about access, out-of-pocket costs, and perfor- 
Table 2. Frequently Asked Questions And Answers About Home Oxygen Therapy

\begin{tabular}{|c|c|}
\hline Category & Sample questions \\
\hline \multirow[t]{2}{*}{ Theme 1: General questions about COPD } & "What is respiratory therapy?" \\
\hline & $\begin{array}{l}\text { "How do I know the questions I should be asking if I'm new to } \\
\text { this?" }\end{array}$ \\
\hline \multirow[t]{2}{*}{ Theme 2: Ways to use oxygen } & "How much oxygen should I use per minute?" \\
\hline & "Can I take a shower with oxygen on?" \\
\hline \multirow[t]{2}{*}{ Theme 3: Symptoms to watch out for } & $\begin{array}{l}\text { "How can I determine whether I have a COPD exacerbation, the } \\
\text { flu, a cold or a m just plain sick?" }\end{array}$ \\
\hline & $\begin{array}{l}\text { "If my oxygen saturation goes below } 88 \% \text { for a short time, how } \\
\text { much damage am I doing to my body?" }\end{array}$ \\
\hline \multirow[t]{2}{*}{ Theme 4: Oxygen safety } & "What are the dangers of having oxygen tanks around?" \\
\hline & "Can you light candles when you are wearing oxygen?" \\
\hline \multirow[t]{2}{*}{ Theme 5: Traveling with oxygen } & "How can I travel with oxygen by air and sea?" \\
\hline & "Can I rent a small machine to travel on a bus for a few days?" \\
\hline \multirow[t]{2}{*}{ Theme 6: Companion treatments } & "Do all people use an inhaler and use oxygen, too?" \\
\hline & "What are the latest surgical procedures available?" \\
\hline \multirow[t]{2}{*}{ Theme 7: Equipment issues and maintenance } & $\begin{array}{l}\text { "Are all the pieces of equipment the same? How can I know } \\
\text { which one is best?" }\end{array}$ \\
\hline & "How often should you change oxygen tubing?" \\
\hline \multirow[t]{2}{*}{ Theme 8: Service issues and advocacy } & $\begin{array}{l}\text { "How do you know what Medicare will cover, what you're } \\
\text { allowed?" }\end{array}$ \\
\hline & "Who do I call if I am not getting proper service?” \\
\hline
\end{tabular}

mance characteristics of different oxygen equipment by region and by insurance provider. ${ }^{42}$

\section{DME Providers}

The role of respiratory therapists in home oxygen services has been diminished dramatically over the past 3 decades. Until the early 2000s, DME providers were competing to provide more services to support patients on home oxygen, including home visits, during which respiratory therapists would provide self-management education and training to patients and their caregivers.

This support to end-users (patients, their families, and other caregivers) was especially important to those who were newly prescribed home oxygen, a group who needed practical information about their equipment (such as $\mathrm{Mr}$ Carter, who did not know how to remove the regulator from a used oxygen cylinder) and options for other types of equipment (eg, portable concentrators, oxygen-conserving devices) that may be better tailored to their current needs.
Reimbursements for home oxygen services have been declining since the 1990s, but they were reduced even more sharply following the implementation of the competitive bidding process by the Centers for Medicare and Medicaid Services in 2009 (initially in selected metropolitan areas, but then nationwide in 2016). ${ }^{35,43}$ Under this competitive bidding process, DME providers have seen a dramatic reduction in reimbursement for home oxygen services (ie, $50 \%$ or more). Such reductions in reimbursements have eliminated the ability of nearly all DME providers to routinely include home visits by respiratory therapists when delivering home oxygen. In most cases, a technician without clinical training now delivers home oxygen equipment to patients. By law, these technicians are not permitted to address any clinical questions from patients or their caregivers, including requests to assess the adequacy of home oxygen equipment or the ability of a patient or their caregivers to use the equipment appropriately.

The majority of orders for home oxygen are written as the patient is being discharged to home following an acute 
cardiopulmonary illness, rather than in the out-patient setting. ${ }^{22,44}$ DME companies are often selected by hospital case managers or discharge planners based on speed of response, which implies a focus on the transaction, not the transition of care. The goal is to make sure the DME provider's truck gets to the patient's home before the oxygen cylinders provided on discharge from the hospital run out. There is a residual belief by clinicians that the DME provider is still a safety net that can provide all the education that is often not feasible to provide in the hospital. This is no longer true. As a respiratory therapist who previously worked in the DME industry explained, "There is now a giant hole in the safety net."

\section{Front-Line Hospital-Based and Out-Patient Clinicians}

Hospital-based clinicians noted varying levels of awareness and ability to provide home oxygen education to patients. Hospital-based physicians report being unable to answer questions about equipment, service, payment, or duration of home oxygen therapy that is initiated in the hospital. Hospital-based nurses are often responsible for reviewing discharge instructions and education materials with patients. However, the discharge process is typically short (5-10 min) and covers the patient's entire care plan. Details about home oxygen therapy are generally limited to what is documented by physicians. Moreover, patients are often overwhelmed with the amount of information provided at hospital discharge and are rarely in a position to ask questions about their home oxygen equipment (which they will often see only once they get home). Hospitalbased respiratory therapists are not often involved in patient education or discharge unless requested. Even then, respiratory therapists acknowledged that they were generally not familiar with oxygen equipment supplied by DME providers and delivered to patients' homes. ${ }^{45}$ Most hospital-based clinicians we interviewed believed that their patients were getting sufficient education and support for home oxygen equipment from the DME providers, apparently unaware of how significantly these services have been reduced in recent years.

Out-patient clinicians recognized that their patients were in need of more education and support but noted that they were also poorly equipped to provide it. Out-patient nurses reported that a substantial proportion of patients do not attend their follow-up appointments and may not undergo a re-evaluation regarding their home oxygen requirements. Nurses are also often unfamiliar with oxygen equipment and services that a patient may receive from a DME provider, and therefore they refer patients to their DME provider for any equipment-specific questions. An out-patient advanced practice nurse also expressed her frustration with the lack of information she could access from the patient's hospitalization:

I only have 20 min with returning patients. It's not a lot of time for the clinical evaluation and patient and caregiver education. I don't think they're doing a walk test in the hospital. I don't know what oxygen company they were set up with. The discharge notes and summary are insufficient, as there is nothing documented related to the home oxygen prescription. There's no communication with the outpatient provider.

\section{Appropriate Home Oxygen Therapy Depends on a Successful Chain of Care During Transition From Hospital to Home}

Discussions with the SHERLOCK stakeholders suggest that a chain of care involving 9 steps across the hospital, home, and out-patient settings is necessary to ensure that patients are successfully initiated on home oxygen therapy during transitions from hospital to home (Fig. 3). ${ }^{25}$ The first 4 steps occur in the hospital, the fifth step occurs at home, and the remaining steps occur in the out-patient setting. Effective hospital-to-home transitions keep patients in a home-to-out-patient loop, while ineffective transitions return patients to a hospital-to-home loop.

A number of stakeholders can be involved in the 9 steps of a hospital-to-home chain of care for home oxygen. In the hospital it could include attending physicians, nurses, respiratory therapists, clinician trainees, discharge planners, and representatives of DME providers. At home, a patient and caregiver might see only a DME technician who delivers the home oxygen equipment; respiratory therapists or other clinicians are rarely involved in the delivery and setup of home oxygen equipment. In the out-patient setting, a primary care provider, pulmonologist, nurses, and clinician trainees might be involved; respiratory therapists are mostly hospital-based due to changes in reimbursement. The number of handoffs between professionals and settings makes it even more critical that each of the 9 steps be supported to deliver optimized home oxygen care.

\section{How to Strengthen the Chain of Home Oxygen Care During Transitions From Hospital to Home}

Thomas L. Petty MD (1932-2009), known as the "father" of modern pulmonary medicine, recognized that it was not enough to demonstrate that LTOT can save lives. ${ }^{46}$ He understood the need to develop and sustain an infrastructure to promote collaboration among stakeholders to translate the evidence into practice. He helped convene a series of 6 LTOT consensus conferences between 


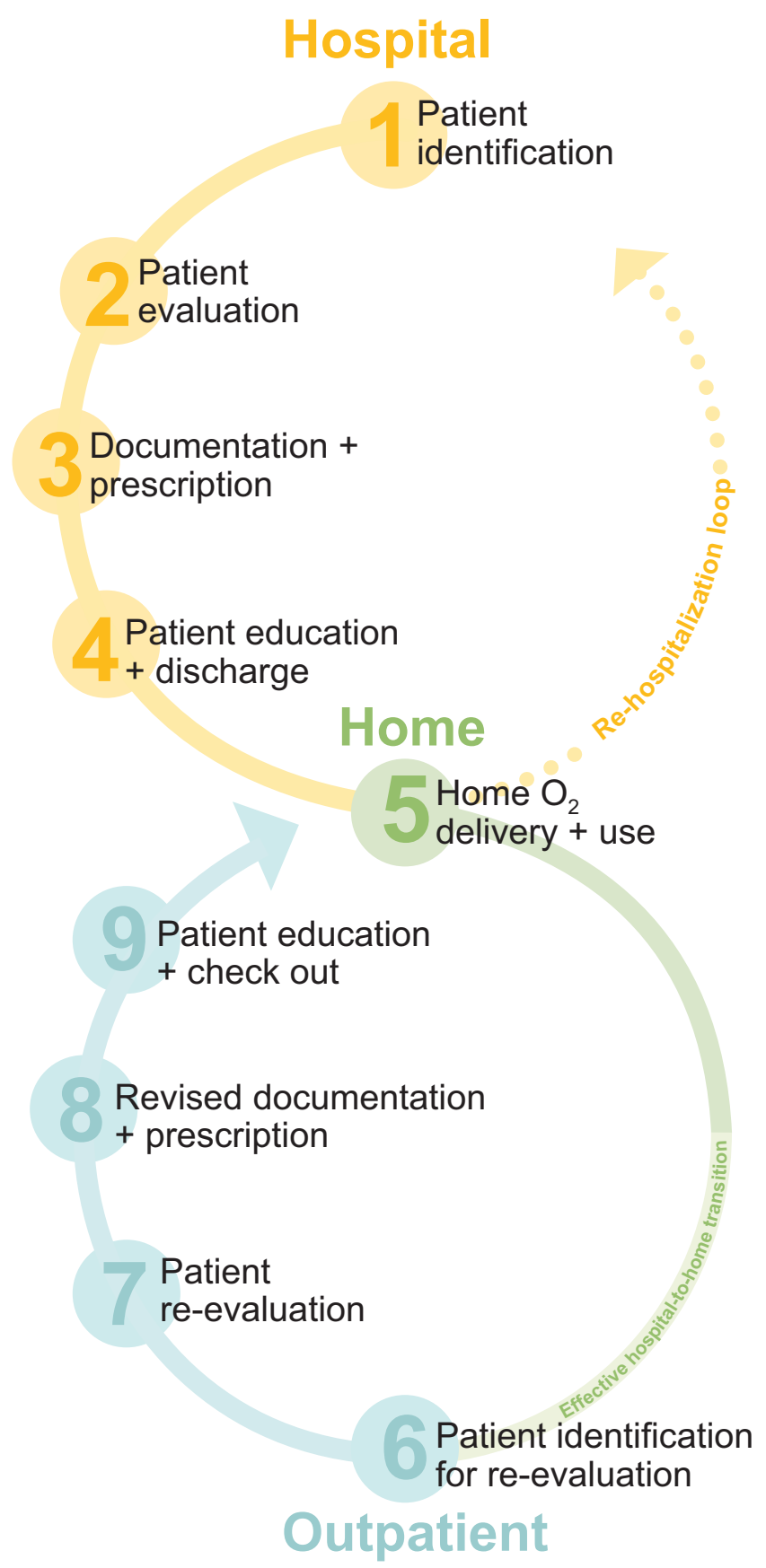

Fig. 3. Chain of home oxygen care during hospital to home transitions.

1986 and 2005.47 Reports from the consensus conferences focused on various topics considered essential to provide appropriate access to life-saving home oxygen therapy, including the need for standards for home oxygen services, adequate reimbursement, medical necessity forms that included appropriate information, patient and clinician education, and identification of gaps in evidence that require further research. Unfortunately, after Dr Petty's death, the LTOT consensus conferences also ceased to exist.

Perhaps more than ever, we need an infrastructure to promote and sustain collaborative efforts among stakeholders to address the gaps in the chain of home oxygen care. We offer the following 2 recommendations: First, resume the LTOT consensus conference series with a full complement of stakeholders; second, leverage the framework proposed by the U.S. COPD National Action Plan.

\section{Resume the LTOT Consensus Conference Series With a Full Complement of Stakeholders}

The chain of home oxygen care involves multiple stakeholders in health care and community settings. Stakeholders include people prescribed home oxygen and the people who care for them; home-based professionals, including DME providers and home health agencies; hospital-based and out-patient clinicians (eg, physicians, nurse practitioners, respiratory therapists, physical therapists); home oxygen product manufacturers; payers (public and private); and policy makers. Building on the work of Dr Petty, convening an annual LTOT consensus conference would provide a mechanism to support stakeholder-supported standards, educational programs, and research to inform policies.

\section{Leverage the Framework Proposed by the U.S. COPD National Action Plan}

The COPD Action Plan is intended to reduce the public health burden of COPD by: (1) empowering people with COPD, their families, and other caregivers; (2) promoting the prevention of COPD and management of COPD across the care continuum; (3) supporting the collection of COPDrelated public health data that drive change and track progress; (4) increasing and sustaining research to improve the care and health of people with COPD; and (5) translating the policies, educations, and other programs into research and public health care actions. ${ }^{37}$ This framework of goals could support a range of efforts to promote the appropriate use of LTOT in patients with COPD, including the development of a trustworthy resource about home oxygen equipment and services for patients and caregivers, the improvement of hospital-to-home transitions for patients prescribed home oxygen therapy, the design and implementation of a national oxygen registry to identify opportunities for quality improvement initiatives, and the conduct of stakeholder-supported hybrid effectiveness/implementation studies to fill care gaps.

\section{REFERENCES}

1. Sekhar K, Rao SC. John Scott Haldane: The father of oxygen therapy. Indian J Anaesth 2014;58(3):350-352. 


\section{Home Oxygen Therapy for Patients With COPD}

2. The Gifford Lectures: John Scott Haldane. Available at: https:// www.giffordlectures.org/lecturers/john-scott-haldane. Accessed June 17, 2019.

3. Haldane JS, Priestley JG. The regulation of the lung-ventilation. J Physiol 1905;32(3-4):225-266.

4. Douglas CG, Haldane JS. The regulation of normal breathing. J Physiol 1909;38(5):420-40

5. Campbell JM, Douglas CG, Haldane JS, Hobson FG. The response of the respiratory centre to carbonic acid, oxygen, and hydrogen ion concentration. J Physiol 1913;46(4-5):301-318.

6. Christiansen J, Douglas CG, Haldane JS. The absorption and dissociation of carbon dioxide by human blood. J Physiol 1914;48(4): 244-271.

7. Haldane JS. The therapeutic administration of oxygen. Br Med J 1917;1:181-183.

8. Haldane JS, Meakins JC, Priestley JG. The respiratory response to anoxaemia. J Physiol 1919;52(6):420-32.

9. Haldane JS, Kellas AM, Kennaway EL. Experiments on acclimatisation to reduced atmospheric pressure. J Physiol 1919;53(3-4):181206.

10. Haldane JS, Meakins JC, Priestley JG. The effects of shallow breathing. J Physiol 1919;52(6):433-453.

11. Haldane JS. A Lecture on acclimatization to high altitudes: delivered to University College Medical Society, Oct 1924. BMJ 1924;2(3333): 885-890.

12. Medical Research Council Working Party. Long term domiciliary oxygen therapy in chronic hypoxic cor pulmonale complicating chronic bronchitis and emphysema. Lancet 1981;1(8222):681-686.

13. Nocturnal Oxygen Therapy Trial Group. Continuous or nocturnal oxygen therapy in hypoxemic chronic obstructive lung disease: a clinical trial. Ann Intern Med 1980;93(3):391-398.

14. Albert RK, Au DH, Blackford AL, Casaburi R, Cooper JA Jr, Criner GJ, et al. A randomized trial of long-term oxygen for COPD with moderate desaturation. N Engl J Med 2016;375(17):1617-1627.

15. Global Initiative for Chronic Obstructive Lung Disease. Global strategy for the diagnosis, management, and prevention of chronic obstructive pulmonary disease: 2019 report. Available at: https:// goldcopd.org/wp-content/uploads/2018/11/GOLD-2019-v1.7FINAL-14Nov2018-WMS.pdf. Accessed April 21, 2019.

16. McDonald CF, Blyth CM, Lazarus MD, Marschner I, Barter CE. Exertional oxygen of limited benefit in patients with chronic obstructive pulmonary disease and mild hypoxemia. Am J Respir Crit Care Med 1995;152(5 Pt 1):1616-1619.

17. Eaton T, Garrett JE, Young P, Fergusson W, Kolbe J, Rudkin S, Whyte K. Ambulatory oxygen improves quality of life of COPD patients: a randomised controlled study. Eur Respir J 2002;20(2): 306-312.

18. Nonoyama ML, Brooks D, Guyatt GH, Goldstein RS. Effect of oxygen on health quality of life in patients with chronic obstructive pulmonary disease with transient exertional hypoxemia. Am J Respir Crit Care Med 2007;176(4):343-349.

19. Moore RP, Berlowitz DJ, Denehy L, Pretto JJ, Brazzale DJ, Sharpe $\mathrm{K}$, et al. A randomised trial of domiciliary, ambulatory oxygen in patients with COPD and dyspnoea but without resting hypoxaemia. Thorax 2011;66(1):32-37.

20. Ameer F, Carson KV, Usmani ZA, Smith BJ. Ambulatory oxygen for people with chronic obstructive pulmonary disease who are not hypoxaemic at rest. Cochrane Database Syst Rev 2014;6:CD000238.

21. Elwyn G, Frosch D, Thomson R, Joseph-Williams N, Lloyd A, Kinnersley P, et al. Shared decision making: a model for clinical practice. J Gen Intern Med 2012;27(10):1361-1367.

22. Chaney JC, Jones K, Grathwohl K, Olivier KN. Implementation of an oxygen therapy clinic to manage users of long-term oxygen therapy. Chest 2002;122(5):1661-1667.
23. Oba Y, Salzman GA, Willsie SK. Reevaluation of continuous oxygen therapy after initial prescription in patients with chronic obstructive pulmonary disease. Respir Care 2000;45(4):401-6.

24. Hardinge M, Annandale J, Bourne S, Cooper B, Evans A, Freeman $\mathrm{D}$, et al. British Thoracic Society guidelines for home oxygen use in adults. Thorax 2015;70(Suppl 1): i1-i43.

25. Sculley J, Cattamanchi A, Gamino AJ, Asche C, Au D, Collins EG, et al. The nine chains of care for home oxygen during hospital-tohome transitions in patients with COPD exacerbations (abstract). 2019 American Thoracic Society International Conference, A7466.

26. Apria Healthcare, Inc. Oxygen cylinder and concentrator systems. Patient instructions. Available at: http://www.aarc.org/education/ online-courses/a-guide-to-portable-oxygen-concentrators. Accessed June 16, 2019.

27. Preferred Health Choice. Oxygen cylinder delivery chart. Available at: https://www.phc-online.com/O2-tank-duration_a/151.htm. Accessed June 16, 2019.

28. American Association for Respiratory Care. A guide to portable oxygen concentrators, 2013. Available at: http://www.aarc.org/ education/online-courses/a-guide-to-portable-oxygen-concentrators. Accessed June 16, 2019.

29. Krishnan JA, Bracken NE, Cerretta S, Gonzalez V, Grabarek M, Holm K, et al. What oxygen equipment do patients with COPD have at home? Ancillary results of the PELICAN study (abstract). Am J Respir Crit Care Med 2017;195:A4715.

30. Katsenos S, Constantopoulos SH. Long-term oxygen therapy in COPD: factors affecting and ways of improving patient compliance. Pulm Med 2011;2011;325362.

31. Ringbaek T, Lange P, Viskum K. Compliance with LTOT and consumption of mobile oxygen. Respir Med 1999;93(5):333-337.

32. Pepin JL, Barjhoux CE, Deschaux C, Brambilla C. Long-term oxygen therapy at home. Compliance with medical prescription and effective use of therapy. ANTADIR Working Group on Oxygen Therapy, Association Nationale de Traitement a Domicile des Insuffisants Respiratories. Chest 1996;109(5):1144-1150.

33. Gauthier A, Bernard S, Bernard E, Simard S, Maltais F, Lacasse Y. Adherence to long-term oxygen therapy in patients with chronic obstructive pulmonary disease. Chronic Respir Dis 2019;16: 1479972318767724.

34. Zaidi F, Lee RS, Buchcic BA, Bracken NE, Jaffe HA, Joo M, et al. Evaluation and documentation of supplemental oxygen requirements is rarely performed in patients hospitalized with COPD. Chronic Obstr Pulm Dis 2017;4(4):287-296.

35. Jacobs SS, Lederer DJ, Garvey CM, Hernandez C, Lindell KO, McLaughlin S, et al. Optimizing home oxygen therapy. An Official American Thoracic Society Workshop Report. Ann Am Thorac Soc 2018;15(12):1369-1381.

36. Jacobs SS, Lindell KO, Collins EG, Garvey CM, Hernandez C, McLaughlin S, et al. Patient perceptions of the adequacy of supplemental oxygen therapy. Results of the American Thoracic Society Nursing Assembly Oxygen Working Group Survey. Ann Am Thorac Soc 2018;15(1):24-32.

37. National Heart, Lung, and Blood Institute. COPD National Action Plan. Available at: https://www.nhlbi.nih.gov/health-topics/ education-and-awareness/COPD-national-action-plan. Accessed June 17, 2019

38. American Association of Respiratory Care, Annual Congress. Available at: http://www.aarc.org/education/live-courses/aarc-meetings/ aarc-congress-2018. Accessed June 17, 2019.

39. COPD Foundation. Available at: https://www.copdfoundation.org/ About-Us/Who-We-Are/About-The-COPD-Foundation.aspx. Accessed June 17, 2019.

40. SHERLOCK Consortium. COPD Education Workshop. Questions and Answers, February 17, 2018. Available at: https://static1.squarespace. 


\section{Home Oxygen Therapy for Patients With COPD}

com/static/59b801bc9f8dce531681f18d/t/5c06f3e01ae6cf9eac250af3/ 1543959520783/Villages_Workshop_Q\&A_20181023.pdf. Accessed June 17, 2019.

41. Consumer Reports. Available at: https://www.consumerreports.org/ cro/about-us/what-we-do/index.htm. Accessed June 17, 2019.

42. Lacasse Y, Krishnan JA, Maltais F, Ekström M. Patient registries for home oxygen. Int J Chron Obstruct Pulmon Dis 2019;14: 1299-1304.

43. Baxter A. Medicare competitive bidding process hurts patients. HealthExec 2018. https://www.healthexec.com/topics/policy/ medicare-bidding-process-hurts-patients. Accessed June 17, 2019.
44. Christopher KL, Porte P. Long-term oxygen therapy. Chest 2011; 139(2):430-434.

45. Tan A-Y, Vines DL, Prieto-Centurion V, Gutierrez-Kapheim M, Krishnan JA, Kallstrom TJ. Respiratory Therapist Home Oxygen for Chronic Obstructive Pulmonary Disease (RIsOTTO) Study: an National survey (abstract). Am J Respir Crit Care Med 2017;195:A7573.

46. Schwarz MI. Thomas L. Petty MD (1932-2009): a tribute. Am J Respir Crit Care Med 2010;181(4):425.

47. Doherty DE, Petty TL, Bailey W, Carlin B, Cassaburi R, Christopher $\mathrm{K}$, et al. Recommendations of the 6th long-term oxygen therapy consensus conference. Respir Care 2006;51(5):519-25. 